\title{
The prevention of Female Genital Mutilation in England: what can be done?
}

E Plugge, Senior Clinical Research Fellow, Centre for Tropical Medicine and Global Health, Nuffield Department of Medicine, University of Oxford, South Parks Road, Oxford OX1 3SY emma.plugge@ndm.ox.ac.uk (corresponding author)

S Adam, community researcher, Centre for Tropical Medicine and Global Health L El Hindi, community researcher, Centre for Tropical Medicine and Global Health J Gitau, community researcher, Centre for Tropical Medicine and Global Health N Shodunke, community researcher, Centre for Tropical Medicine and Global Health O Mohamed-Ahmed, Public Health Registrar, National Perinatal Epidemiology Unit, University of Oxford, Old Road Campus, Oxford OX3 7LF 


\section{The prevention of Female Genital Mutilation in England: what can be done?}

\section{Abstract}

Background: Female genital mutilation (FGM) is a global public health issue. Women in the UK are at risk of FGM and its adverse health consequences but little is known about its practice. Since 1985 it has been a criminal offence to perform FGM in the UK and further legislation has tightened the law but FGM continues.

Methods: Four community researchers from the Kenyan, Nigerian, Somalian and Sudanese communities in Oxford conducted focus groups and interviews with 53 people to understand the communities' beliefs about how best to prevent FGM.

Results: Participants believed that the current UK legislation alone was not sufficient to tackle FGM and might in fact be counterproductive by alienating communities through its perceived imposition. They felt that there had been insufficient consultation with affected communities, awareness raising and education about the legislation. Community-led solutions were the most effective way to tackle FGM.

Conclusions: FGM adversely affects communities globally. In the UK, researchers from affected communities gathered data demonstrating the feasibility and importance of involving communities in FGM prevention work. Further research is needed to understand how best to prevent FGM in affected communities and, very importantly, to examine the impact of the UK legislation relating to FGM.

Keywords women, female genital mutilation, prevention, community engagement 


\section{The prevention of Female Genital Mutilation in England: what can be done?}

\section{Introduction}

Female genital mutilation (FGM) is an important global public health issue. It is defined by the World Health Organization as all procedures that involve partial or total removal of the external female genitalia, or other injury to the female genital organs for non-medical reasons [1]. There are no known health benefits but the adverse health effects have been well documented, including haemorrhage, pain, shock, infection, urination problems, mental health problems and an increased risk of adverse obstetric outcomes [2,3,4]. Over 200 million girls and women worldwide are living with the effects of FGM [5] and every year some 3 million girls and women are at risk of FGM [6]. Globally FGM is concentrated in a band of sub-Saharan countries from the Atlantic Coast to the Horn of Africa although it is also an issue in many other countries including South East Asia [7].

FGM is an important public health issue in the United Kingdom (UK) with an estimated 103,000 women aged 15-49 living with FGM in England and Wales in 2011 [8]. Most affected women live in urban areas where people born in countries where FGM is practised are most likely to live and London has the highest prevalence at 21.0 per 1,000 women [8]. Since 1985, it has been a serious criminal offence to perform FGM in the UK, under the Prohibition of Female Circumcision Act. The Female Genital Mutilation Act (2003) tightened this law to include FGM carried out overseas by UK nationals or permanent residents, and more recently the scope has been extended by the Serious Crime Act in 2015 [9]. The 2015 Act also introduced a mandatory reporting duty, requiring all health and social care practitioners and teachers in England and Wales to report cases of FGM in girls (under 18) directly to the police [10]. However despite this legislation, there have been no successful prosecutions for performing FGM in the UK and it remains unclear how many cases of FGM have been reported though mandatory reporting [11]. Furthermore FGM is still being practised and recent UK governmental guidance recognises that legislation must be combined with other approaches to prevent FGM [12].

Research from Norway with the Somali community showed that attitudes towards FGM appear to change with time after arrival in the host country, with people who had lived in Norway for less than four years being twice as likely to support the continuation of FGM compared to those who had lived in Norway for over 14 years [13]. Another study showed that many from the Somali community in Oslo considered that FGM was 'harmful, barbaric, and un-Islamic' [14]. Little is known about effective interventions to prevent FGM however. A systematic review examining the effectiveness of interventions designed to reduce the prevalence of FGM found that community empowerment through education and multifaceted community activities were likely to be more effective than training health personnel. Educating female students may have led to a small increase in knowledge about FGM. However the quality of the six included studies was low and all were based in Africa. More definitive research is needed to determine effective interventions to prevent FGM [15].

FGM rates in Oxford are considered to be high compared to many places in England and Wales at over 7 per 1,000 women. Prevention is a key priority within the strategy developed by the multi-agency group formed to respond to FGM in Oxfordshire [16]. This group specifically identified the importance of working directly with communities affected by FGM to explore ways of preventing FGM. The Public Health department within Oxfordshire County Council (OCC) who are members of the strategy group, funded researchers within the University of Oxford to work with affected communities locally to explore ways in which to prevent FGM in Oxfordshire using participatory action research as a tool for community engagement based on tools developed by Coventry University's 'REPLACE-II' project [17]. This paper focuses on the findings from that project which relate to the communities' perceptions and views about how best to prevent FGM. 


\section{Methods}

Public Health, OCC, identified four community researchers (JG, NS, SA, LEH) who were active members of the Kenyan, Nigerian, Somalian and Sudanese communities in Oxford. The researchers participated in four full days of training which included basic training on FGM awareness, training on running focus groups, analysing qualitative data and ethical research conduct. Each community researcher conducted 2-3 focus groups with her community members. The researchers were already involved in local community events and groups and used these to recruit participants, approaching people with invitations and information sheets explaining the research to them.

The community researchers used purposive sampling to recruit younger, unmarried women for one group and then older, married women for another group. There was also a group of Nigerian men and a group of three Somali women spanning three generations. The composition of these groups had been discussed extensively to ensure that participants within each group were appropriately homogenous so that the views they expressed were not likely to be very different to those of their fellow participants as this might stifle participation [18]. Two interviews with older Kenyan women were conducted in addition to the focus groups.

The focus groups took place in a private room in a local community centre and lasted between 90 minutes and three hours. Two community researchers were present; the facilitator would be the researcher from that community and the co-facilitator one of her fellow community researchers. The focus groups with Sudanese women were the exception - here the co-facilitator was an Arabic-speaking public health doctor of Sudanese heritage who worked on FGM issues at OCC.

All but one of the groups/interviews were recorded. These were then transcribed into English. All data were analysed independently by two people. Having familiarized ourselves with the data, we carried out thematic analysis to identify and categorise major themes and sub-themes. We reviewed and refined the themes to ensure that they formed a coherent pattern and to re-code if necessary and examined the data for deviant cases. We discussed in depth the interpretation of the data and the few minor differences in interpretation were resolved by discussion. NVivo 11 software was used to facilitate data coding and organisation into conceptual categories and themes.

The University of Oxford Medical Sciences Inter-divisional Research Ethics Committee granted approval for the study.

\section{Findings}

\section{Participants}

We conducted eight focus groups and two interviews; the details of the participants are provided in Table 1. Consent was given by all but one group for recording.

Table 1. Focus group \& interview participants

\begin{tabular}{|l|l|}
\hline Group/interview & Number of Participants \\
\hline Young Sudanese Mothers & 6 \\
\hline Older Sudanese mothers/grandmothers & 10 \\
\hline Women from Somalia aged $35-49$ years & 4 \\
\hline Women from Somalia aged $20-55$ years & 5 \\
\hline Women from Somalia aged 19 -83 years & 5 \\
\hline Young woman of Kenyan origin (aged <25 years) (interview) & 1 \\
\hline
\end{tabular}




\begin{tabular}{|l|l|}
\hline Women of Kenyan origin aged $18-25$ years & 4 \\
\hline Women of Kenyan origin over 60 years old (interview) & 2 \\
\hline African Women (Nigeria, Kenya, Sudan) aged $25-54$ years & 7 \\
\hline Nigerian men aged $31-60$ years old & 9 \\
\hline
\end{tabular}

\section{Key themes}

Within groups and across communities there was unanimity that the solutions to the ongoing practice of FGM lay within the affected communities themselves; Government legislation, ostensibly aimed at preventing FGM, created more problems than it solved.

\section{Perceived problems with the legislation}

Participants believed that it was possible to prevent FGM but there were differing views over the Government's recent legislative changes extending the criminalisation of FGM and the introduction of mandatory reporting. Some saw it as helpful but appreciated the complexity of the issue.

'It's a good thing there's a law here, but back home, I think if a law like that is enacted then it will drive people to be more secretive about female circumcision or mutilation and that might even cause more harm. People don't talk about it but it's still going on in the background, so it's very important that a lot is done, to understand all the drivers responsible, to understand why people circumcise females in the first place. And when we understand those drivers, we should try to let change start from within.'

Group with African Women (Nigeria, Kenya, Sudan) aged 25 - 54 years

Indeed, many participants perceived that the legislation had been imposed on them and saw this as problematic. More should have been done to raise awareness of the legislation within affected communities.

'...You really need to educate people and bring awareness to the community [about] the consequences of the health and legal complications. I think people need to be educated and heal first, healing is the best treatment rather than punishing. There is a question here, 'am I aware of what I have been punished [for[]?'

Women from Somalia aged $20-55$ years

Because the law was not seen as supportive to these communities, it would be perceived as punitive, as summed up succinctly by one man from the Nigerian community, 'it's another stick to beat us with.' Furthermore, at a time when many of these same communities felt they were being unfairly judged and targeted because of counter terrorism measures in particular, there was considerable potential for the legislation to alienate these communities. The imposition of yet another law was seen as punitive and likely to create suspicion or even conflict between communities and law enforcement bodies.

'My son's detail is given to the police because of his name and now my daughter's detail is given to the police because of FGM mandatory report! I run away from civil war, and I come and put my children on these lists.'

Women from Somalia aged $35-49$ years

Participants felt that the legislation would have limited effectiveness when there were powerful influences and links with 'home' countries. Family overseas might want the practice to continue and FGM could take place in these countries despite the UK legislation and its extra-territorial reach. The legislation would be likely to drive the practice further underground.

$P 1$. 'The law might be fine here but it will not change the reality back there

$P 2$. If there are no laws back there people will go home to do it and come back'

Young Sudanese Mothers Group 
'You bring the law without awareness and then you try to implement the law - this practice can always go undercover and you could just be driving these communities to continue what they know as their tradition, their culture, and it's bringing identity to them... They have to remember this is cultural practice and it runs deep, so just coming out with the legislation and then looking for prosecution would not solve problems.'

Women from Somalia aged $20-55$ years

\section{Mandatory reporting}

The duty on health professionals to report FGM was singled out as particularly counterproductive. Participating communities felt that it was having a profound effect on the way they viewed their interactions with GPs. Confidentiality could no longer be guaranteed, undermining an important feature of the doctor-patient relationship, and this was likely to deter people from seeking help.

'As my sister here said, the mandatory report is creating big problem because people go to the doctors as a place of trust and confidentiality but if they doubt that, again, it is going to be big problem. Why should I go to the doctors if I do not trust him or her anymore? And that is really huge damage to the community and sadly it's happening.'

Women from Somalia aged $20-55$ years

\section{Solutions: the need for community engagement and education}

Participants believed that the communities themselves held the key to tackling FGM effectively. There should be education and awareness campaigns about FGM and its legislation, led by the communities.

'[The] most important thing is when talking to and working with people at grassroots, you have to be accepted by them, you have to be convincing to them, for example, you cannot go dressed in unacceptable way- they have to accept you. So we need people like this to work with them convincing people.'

'I think education should come more from within, from people like them.'

African Women (Nigeria, Kenya, Sudan) aged $25-54$ years

The awareness raising and education could take many forms, but should include written materials (leaflets, etc.) and media releases but also interactive sessions with communities and in schools. The idea of 'community champions' was raised:

I believe community leaders, community champions, let's call them that, community health champions, because their ways of communicating amongst the community that are very specific to communities right, if you really want arrive at this place of wellbeing, I think those are fundamentally an important approach.'

Women from Somalia aged $35-49$ years

Participants felt education and awareness raising about FGM was more likely to be successful if it was done in the context of wider sexual health issues, particularly targeting the transition period from childhood to adulthood. They felt that there was a need for general education about these issues which were rarely spoken about.

'FGM is a problem but we don't see it as one, we don't talk about sex, many women don't enjoy sex and FGM prevent them from enjoying sex.... most African women don't get the drive, don't enjoy sex they just satisfy their husband-it's just like a duty. We don't talk about sex and that is why they're living with the consequences of FGM and still don't talk about it.'

African Women (Nigeria, Kenya, Sudan) aged $25-54$ years 
'Especially women, we need a space for us, a space where we can explore without being judged. Being judged for having sex at whatever age. We didn't grow up in a permissive society. We need that space as black women so that we can explore that. Another thing is you know I think like, I don't know whether it is possible to have our own sexual clinic where we find a black women who understand what we are talking about. Where you tell your white friends and they are like, what are you talking about? So that you don't get the stigma of you are just from the bundus, you are backward...'

Group with women of Kenyan origin aged $18-25$ years

Participants, both male and female, felt that for any interventions against FGM to be effective, men should be engaged. Many participants also identified the importance of engaging younger people. There was a need for education in schools and youth groups.

P1. I think change comes from the new generations, and it starts at school; kids need to be taught this at school. We need to tell them that in this country we had this practice that people did it for these reasons but it has these risks. Most importantly they must be educated from early that it has no linkages to religion. My second recommendation is about men involvement...

P2. Yes, men are crucial in this

P1. Men must know that it has nothing to do with sexual pleasure or satisfaction. My final one is speaking about the risks of FGM, being elaborate on this to really demonstrate the harm like now we are seeing in the media, for instance, on adverts the risks of talking on the phone while driving. People should not be shy about this - they must dig deep and really talk about these things to show people. This is what I perceive.'

Young Sudanese Mothers Group

\section{Discussion}

\section{Main finding of this study}

The participating communities had clear ideas about how FGM is best prevented within their communities. There was an overwhelming feeling that the current UK legislation was not sufficient to tackle FGM and might in fact be counterproductive by alienating communities through its perceived imposition. Participants felt that there had been a notable absence of consultation with affected communities, awareness raising and education about the legislation. They believed that communityled solutions were the most effective way to tackle FGM. They needed space for discussions, education and awareness raising initiatives and, perhaps, 'community health champions'.

\section{What is already known on this topic}

The participants in this study emphasised again and again the need for education about FGM, its harmful effects and the implications of the legislation. A study in 2014 by Africans Unite Against Child Abuse (AFRUCA), a national charity, explored attitudes towards and experiences of FGM by African communities in Greater Manchester [17]. The AFRUCA study also found a 'gaping hole' in terms of education and the provision of support for FGM affected communities. However, a European Union funded study of Somali and Sudanese communities in the Netherlands and the UK found that 'People were keen to stress that awareness levels about the issue of FGM were high in their communities.' [15] This study identified the role of media being key in providing people with information. They noted that documentaries about FGM would spark debates and reflection on FGM. In the Netherlands in particular, affected communities identified the media as their key source of knowledge of FGM legislation. In Oxfordshire there are face-to-face education initiatives run in schools by a local charity which works to help prevent FGM, Oxford Against Cutting, through education and awareness raising initiatives in schools and communities.

Participants in this study emphasised the need to involve men in all efforts to end FGM. The AFRUCA study also noted, 'If we can change the male mind-set it will contribute significantly to the way FGM is 
perceived' [19] The REPLACE study found that men and women within families rarely discussed FGM. Women perceived that men wanted women to undergo FGM but most male participants stated that they actually did not want this [17]. Clearly this is an area where further work needs to be done.

\section{What this study adds}

The study also found considerable ambivalence about the UK law as many participants felt that FGM should not be a criminal offence because it is 'part of their culture'. Furthermore there were concerns about its imposition on communities; these concerns were rooted in the way it had been imposed without any meaningful consultation or awareness raising activities. Participants highlighted the potential adverse effects: alienating communities, driving the practice underground and undermining the doctor-patient relationship. Although the potential to alienate communities has been noted elsewhere [19], the potential adverse effects relating to the doctor-patient relationship have not been reported elsewhere.

That the communities themselves are the key to tackling FGM effectively was an important finding. Participants were clear that the initiatives aimed at tackling FGM should come from within the communities. The need to strengthen community based prevention efforts has also been highlighted by other research $[15,20]$. However, subsequent to this work, the community researchers have successfully developed and delivered two unique bespoke community days locally in which FGM awareness initiatives have been embedded in activities and awareness raising about other health topics of interest.

\section{Limitations of this study}

This work focused on the prevention of FGM in specific communities in Oxford. The researchers were embedded in their communities, enabling them to engage their communities and the rich data produced reflects their skills as researchers and the trust established within their communities. Unfortunately because of resource constraints this work was only conducted in four communities and the findings cannot be generalised to other affected communities from other nations or even other affected communities from Kenya, Nigeria, Somalia and Sudan in other areas in the UK. Nevertheless there was considerable consistency of themes across groups and communities and resonance with the limited research from elsewhere. Resource constraints also meant that the focus groups and interviews were transcribed straight into English rather than being transcribed into the language in which they were conducted and translated as appropriate. However, although more nuanced meanings may have been lost, it is unlikely that this would have affected the key messages.

\section{Conclusions}

FGM is a health issue that continues to adversely affect communities in the UK. Researchers from affected communities effectively gathered data which demonstrated that these communities believed that activities aimed at tackling FGM should come from within the communities themselves and should be embedded in broader health initiatives focused on health issues regarded as important by those communities. This work demonstrated the feasibility and importance of involving communities in FGM work. Further research is needed to understand communities' perceptions and views about how best to prevent FGM in other affected communities in the UK and, very importantly, to examine the impact of all legislation relating to FGM. 


\section{Acknowledgments}

The University of Oxford is grateful to Public Health, Oxfordshire County Council for providing a grant for the cost of this study. Any views expressed in this publication are those of the authors and not necessarily those of the Public Health, Oxfordshire County Council, which is not responsible for them. We are particularly grateful to Kate Austin, Kate Jordan and Jackie Wilderspin from Public Health, Oxfordshire County Council. Alison Chapman, Saater Ikpaahindi, Clare Robertson and Mehrunisha Suleman provided excellent training and/or advice in their areas of expertise. This project would not have been possible without the participation of the communities themselves. We are incredibly grateful that they gave up their time to participate and that they felt able to share their views, insights, wisdom and experience with us.

\section{References}

1. World Health Organization Female genital mutilation Fact sheet. http://www.who.int/mediacentre/factsheets/fs241/en. Updated February 2017

2. World Health Organization. WHO guidelines on the management of health complications from female genital mutilation. World Health Organization, Geneva, Switzerland 2016.

3. WHO study group on female genital mutilation and obstetric outcome. Female genital mutilation and obstetric outcome: WHO collaborative prospective study in six African countries. Lancet. 2006;367(9525):1835-41.

4. Berg RC, Denison E, Fretheim A. Psychological, social and sexual consequences of female genital mutilation/cutting (FGM/C): a systematic review on quantitative studies. Report from Kunnskapssenteret nr 13-2010. Oslo: Nasjonalt kunnskapssenter for helsetjenesten; 2010.

5. United Nations Children's Fund. Female genital mutilation/cutting: a global concern. Geneva: UNICEF; 2016. http:// data.unicef.org/resources/female-genitalmutilation-cutting-a-global-concern

6. Female genital mutilation/cutting: a statistical overview and exploration of the dynamics of change. New York: United Nations Children's Fund; 2013. http://data.unicef.org/resources/female-genitalmutilation-cutting-a-statisticaloverview-and-exploration-of-the-dynamics-of-change

7. United Nations Children's Fund. Female Genital Mutilation/Cutting: A statistical overview and exploration of the dynamics of change. United Nations Children's Fund (UNICEF), 2013

8. Macfarlane A, Dorkenoo E. Prevalence of Female Genital Mutilation in England and Wales: National and local estimates. City University and Equality Now, London 2015.

9. Female Genital Mutilation legal guidance, CPS guidance

http://www.cps.gov.uk/legal/d_to_g/female_genital_mutilation/

10. Home Office procedural information for mandatory reporting published 20.10.2015

https://www.gov.uk/government/uploads/system/uploads/attachment_data/file/469448/FGM-

Mandatory-Reporting-procedural-info-FINAL.pdf

11. Gerry F, Rowland A, Fowles S, Smith S, Hodes D, Creighton S. Failure to evaluate introduction of female genital mutilation mandatory reporting. Arch Dis Child. 2016 Aug;101(8):778-9. doi: 10.1136/archdischild-2016-311000. Epub 2016 Jun 8.

12. HM Government. Multi-agency practice guidelines: female genital mutilation. London: The Stationery Office, 2014.

https://www.gov.uk/government/uploads/system/uploads/attachment_data/file/380125/MultiAgenc yPracticeGuidelinesNov14.pdf

13. Gele AA, Johansen EB, Sundby J. When female circumcision comes to the West: Attitudes toward the practice among Somali Immigrants in Oslo. BMC Public Health 2012 12:697. 
14. Gele AA, Kumar B, Harsløf Hjelde K, Sundby J. Attitudes toward female circumcision among Somali immigrants in Oslo: a qualitative study. Int J Womens Health. 2012; 4: 7-17.

15. Denison E, Berg RC, Lewin S, Fretheim A. Effectiveness of Interventions Designed to Reduce the Prevalence of Female Genital Mutilation/Cutting. Oslo, Norway: Knowledge Centre for the Health Services at The Norwegian Institute of Public Health (NIPH); 2009.

16. Oxfordshire Safeguarding Children Board Strategy to prevent FGM 2014-2017. 2014. http://oxfordshirescb.proceduresonline.com/pdf/strategy to prevent fgm.pdf

17. Barrett H, Brown K, Beecham D, Otoo-Oyortey N, Naleie Z. Researching female genital mutilation intervention programmes linked to African communities in the EU (REPLACE). Pilot toolkit for replacing approaches to ending FGM in the EU - implementing behaviour change with practising communities. 2011. http://www.replacefgm2.eu/resource/replace-toolkit.aspx

18 Fitzpatrick R, Boulton M. Qualitative methods for assessing health care. Quality in Health Care 1994;3:107-13.

19. Voices of the Community: Exploring Female Genital Mutilation in the African Community across Greater Manchester. AFRUCA 2015.20. Brown E, Porter C. The Tackling FGM Initiative: Evaluation of the Second Phase (2013-2016). Options UK, July 2016.

20. Brown E, Porter C. The Tackling FGM Initiative: Evaluation of the Second Phase (2013-2016). Options UK, July 2016. 